Article

\title{
Evaluation of Changes in Individual Community-Related Empowerment in Community Health Promotion Interventions in Estonia
}

\author{
Anu Kasmel ${ }^{1,2, *}$ and Pernille Tanggaard ${ }^{2}$ \\ 1 Institute of Political Science and Governance, University of Tallinn, Narva mnt. 10-120, \\ Tallinn, Estonia \\ 2 Institute of Public Health, University of Southern Denmark, Niels Bohrs Vej 9-10, 6700 Esbjerg, \\ Denmark; E-Mail: ptandersen@health.sdu.dk \\ * Author to whom correspondence should be addressed: E-Mail: anu.kasmel@gmail.com; \\ Tel: +372-51-05-621; Fax: +45-6550-42-83.
}

Received: 4 April 2011 / Accepted: 10 May 2011 / Published: 25 May 2011

\begin{abstract}
This study assessed changes in community members' ratings of the dimensions of individual community related empowerment (ICRE) before and two years after the implementation of an empowerment expansion framework in three community health promotion initiatives within the Estonian context. We employed a self-administered questionnaire, the adapted mobilisation scale-individual. As the first step, we investigated the multidimensional nature of the ICRE construct and explored the validity and reliability (internal consistency) of the ICRE scale. Two datasets were used. The first dataset comprised a cross-sectional random sample of 1,000 inhabitants of Rapla County selected in 2003 from the National Population Register, which was used to confirm the composition of the dimensions of the scale and to examine the reliability of the dimensions. The second dataset comprised two waves of data: 120 participants from three health promotion programs in 2003 (pre-test) and 115 participants in 2005 (post-test), and the dataset was used to compare participants' pre-test and post-test ratings of their levels of empowerment. The content validity ratio, determined using Lawshe's formula, was high (0.98). Five dimensions of ICRE, self-efficacy, intention, participation, motivation and critical awareness, emerged from the factor analysis. The internal consistency $(\alpha)$ of the total empowerment scale was 0.86 (subscales self-efficacy $\alpha=0.88$, intention $\alpha=0.83$, participation $\alpha=0.81$ and motivation $\alpha=0.69$; critical awareness comprised only one item). The levels of ICRE dimensions measured after the application of the empowerment
\end{abstract}


expansion framework were significantly more favourable for the dimensions self-efficacy, participation, intention and motivation to participate. We conclude that for Rapla community workgroups and networks, their ICRE was rendered more favourable after the implementation of the empowerment expansion framework.

Keywords: individual community related empowerment; social change; health promotion; empowerment evaluation; Estonia; Eastern Europe

\section{Introduction}

Researchers, practitioners and politicians have all recognised that empowerment represents a core concept in health promotion. Its importance has been highlighted in the Alma-Ata Declaration [1] and the Ottawa Charter [2]. Empowerment is defined as a process whereby communities, organisations and/or individuals are enabled to assume power to act effectively to change their lives [3-6]. Embedded within this definition is a point that is crucial for research on empowerment: the level of analysis at which the construct is conceptualised, i.e., individual, organisational and/or community levels of empowerment [7]. The scope of the current study is at the level of individual communityrelated empowerment (ICRE).

Individual empowerment (IE) is the expression of the empowerment construct at the level of the person and reflects one's freedom to decide what goals to pursue [8]. IE has been seen as an effective strategy in improving employees' health [9], empowering low income mothers [10], enabling cancer patients [11], empowering young people [12] and in improving adult outpatient mental health [13].

However, despite the impressive body of published studies on empowerment [3], health promotion practitioners still have few tools for the measurement of the empowerment construct. Many authors have argued that ICRE is a prerequisite for community empowerment and social change $[8,14,15]$. Therefore, in evaluating the empowering processes, the evaluation of community empowerment might be supported by and benefit from the measurement of ICRE.

The current study is a part of a wider evaluation that included two parallel assessments: an internal evaluation of the organizational domains of community empowerment and an external evaluation of the ICRE. To the best of our knowledge, no research on ICRE has previously been undertaken in Estonia.

\subsection{Aim of the Study}

The main aim of the current study was to assess changes in ICRE in a sample of community members two years after the application of the empowerment expansion framework (see below) in the community of Rapla, Estonia. The specific objectives were as follows:

(1) to assess the construct validity of the ICRE scale;

(2) to investigate the multidimensional nature of the ICRE construct;

(3) to assess the reliability of the ICRE scale; and; 
(4) to assess changes in participants' ratings of the dimensions of the ICRE before and after the application of the empowerment expansion framework.

\subsection{Theoretical Framework}

Several authors have defined empowerment as a construct that links individual strengths and competencies, natural helping systems, and proactive behaviours to matters of social policy and social change. Psychological empowerment is a process by which individuals gain control over their lives [4]. Empowerment is associated with feelings of competence to change a situation and with expectations of positive outcomes for one's efforts [7,14,15]. Individual empowerment begins with an individual belief that what one is trying to accomplish is possible to achieve.

Researchers have noted that the development of a universal measure of individual empowerment may not be a feasible or appropriate goal, as empowerment differs among individuals, contexts and times [16]. Furthermore, empowerment is not understood as merely an individualistic characteristic; rather, it is related to perceived goals in one's environment. The measurement of individual empowerment is problematic because empowerment may manifest in different forms of perceptions, behaviour, competencies and actions, and moreover, it may fluctuate over time [3].

Several researchers have identified somewhat different scales for the measurement of individual empowerment depending on the context and/or specificity of study group. Zimmerman [16] defined three components of IE: intrapersonal, interactional and behavioural. The intrapersonal component includes community-specific self-efficacy, motivation and intention to take action and control in an individual's community. The interactional component refers to critical awareness and understanding of a given context. The behavioural component includes participation in collective action. In the context of ethnic identity, Gutierrez [17] specified group identification as a psychological component of empowerment for individuals. Parsons [18] identified characteristics of empowerment in the context of mental health services. One characteristic identified was the degree to which clients develop a critical awareness or critical thinking regarding system dynamics within the family or community with relation to power. McWhirter [19] described skill development, a characteristic that stresses skills in decision making and socialisation. Akey et al. [20] utilised data from 293 parents of children with disabilities living in three states in the USA and participating in family support programs aimed at empowering parents. The scale developed by these authors originally contained three subscales: attitudes related to control and competence, critical skills and knowledge, and participatory behaviour. Speer and Peterson [21] elaborated a 27-item scale for the measurement of IE and reported psychometric properties of a scale from a sample of 974 randomly selected people. They identified cognitive, emotional, and behavioural dimensions in community-organising contexts. The applicability of their measure was broad. However, they all recognised that modifications need to be made on the basis of the variety of contexts and settings in which empowerment may be applied.

Empowerment theory proposes that empowerment takes on different meanings in different settings [16]. The definition of ICRE employed in the current study combines multiple components: self-efficacy with self-confidence [22-24]; involvement in collective action (participation); motivation to be involved in community action [25]; willingness and intention to take action in the public domain [25]; and critical awareness that community issues are serious [9,26]. 
Self-efficacy is an individual's confidence in their personal capability to organise and execute the course of action required to deal with prospective situations and belief in their capability to regulate their motivation, thought processes, emotional stages and the social environment, as well as behavioural attainment $[4,14,25]$. It is the belief that one has the skills and ability to achieve goals accompanied by perceived improvements in knowledge and skills through participation in community problem-solving processes [27]. Perceived self-efficacy with regard to dealing with community issues is associated with a sense of community [28,29] and with social action on community issues $[14,15,25]$. Perceiving that one can solve community problems is a prerequisite for community involvement [30].

Participation is the involvement in any community action that an individual attends without pay to achieve a common goal and/or social change [25,31].

Motivation is the belief that one should participate in community problem-solving processes as a responsibility to others $[25,32]$. Thus, people are motivated by a sense of moral responsibility to redress practices or change conditions that they perceive to be unfair [33].

Intention to participate is an anticipated outcome that is intended or that guides one's planned action [25].

Critical awareness is the sense of the importance of community issues and understanding of the purposes of community action [27]. Critical comprehension and knowledge of social and political contexts is a prerequisite for the cultivation of both individual and collective resources and skills related to social action [23].

Essentially, ICRE is an active type of community orientation in which an individual wishes and feels able to shape his/her role and context [16]. The applicability of this measure is broad, but modifications need to be made on the basis of the variety of social work settings in which empowerment may be applied.

\subsection{Context and Settings}

The current study was undertaken in Rapla County, Estonia, which is a small agrarian inland community of 37,000 inhabitants. There is high employment rate and relative poverty of Rapla County's population is high in comparison to other regions of Estonia [34]. Several health promotion interventions have been initiated in Rapla, which have been directed to different health issues. Until the current study, previous assessments of health promotion initiatives were mainly focused on measuring changes in health outcomes. In 2002 an empowerment expansion study was designed simultaneously to expand empowerment in communities and to assess changes in the organizational domains of community empowerment and also in ICRE of the participants involved in community health promotion programs [35]. This evaluation was premised on a two-pronged approach that comprised an internal evaluation undertaken by the community members and an external evaluation undertaken by a person external to the programs. The current study is an external evaluation of the ICRE. The study involved participants from three community health promotion initiatives in Rapla County: the Safe Community program; Drug Abuse and AIDS Prevention programme; and Elderly Quality of Life program. Short description of the essence of community health promotion interventions is presented in Table 1. 
Table 1. Study sample: three community health promotion and disease prevention initiatives in Estonia [35].

\begin{tabular}{ll}
\hline Community Initiative & \multicolumn{1}{c}{ Description } \\
\hline Safe Community & $\begin{array}{l}\text { This program was initially a bottom-up initiative guided by a community } \\
\text { workgroup. It later involved representatives from municipalities and decision } \\
\text { makers from different sectors and had a large network in the county. It } \\
\text { consisted of a combination of a top-down and bottom-up initiative financed } \\
\text { on a yearly basis by a health promotion fund }\end{array}$ \\
\hline $\begin{array}{l}\text { Drug Abuse and } \\
\text { AIDS Prevention }\end{array}$ & $\begin{array}{l}\text { objectives and a national action plan. This program was financed by the state } \\
\text { budget and guided by a local coalition composed of representatives from } \\
\text { different organisations, authorities and sectors in the county }\end{array}$ \\
\hline $\begin{array}{l}\text { Elderly Quality } \\
\text { of Life }\end{array}$ & $\begin{array}{l}\text { A bottom-up initiative. The workgroup consisted of elderly women who } \\
\text { were interested in improving the life of elderly citizens in their community. }\end{array}$ \\
& $\begin{array}{l}\text { The aim of the program was to avoid the exclusion of older people, and the } \\
\text { group made efforts to keep elderly citizens involved socially }\end{array}$ \\
\hline
\end{tabular}

\subsection{Empowerment Expansion Framework}

The community workgroups constructed an empowerment expansion framework (Figure 1) to achieve and assess changes in empowerment and health in the three different programs that were being implemented [35]. The framework was based on models of empowerment evaluation, as suggested by Fettermann [36], and the parallel tracks model elaborated by Laverack [37]. Empowerment evaluation is a process through which community members in collaboration with health promotion practitioners learn to evaluate their own programs and work together toward the improvement of the quality of their common program using several pragmatic steps.

Empowerment evaluation is the use of evaluation concepts, techniques, and findings to foster improvement and self-determination [36]. The advantage of the model is that it suggests a clear step-by-step empowering guide. Its limitation is that it does not suggest how to measure changes in empowerment [35].

The 'parallel tracks' program planning model elaborated by Laverack [37] integrates an empowerment approach within an issue-specific approach ensuring focus on both empowerment process goals and issue-specific goals. The advantage of this model is that by clarifying and distinguishing empowerment domains, participants are able to easily assess changes in empowerment during an intervention course and measure empowerment domains. The limitation of this model is that it does not clearly demonstrate the precise steps involved in the empowerment approach. 
Figure 1. Empowerment expansion framework* [35].

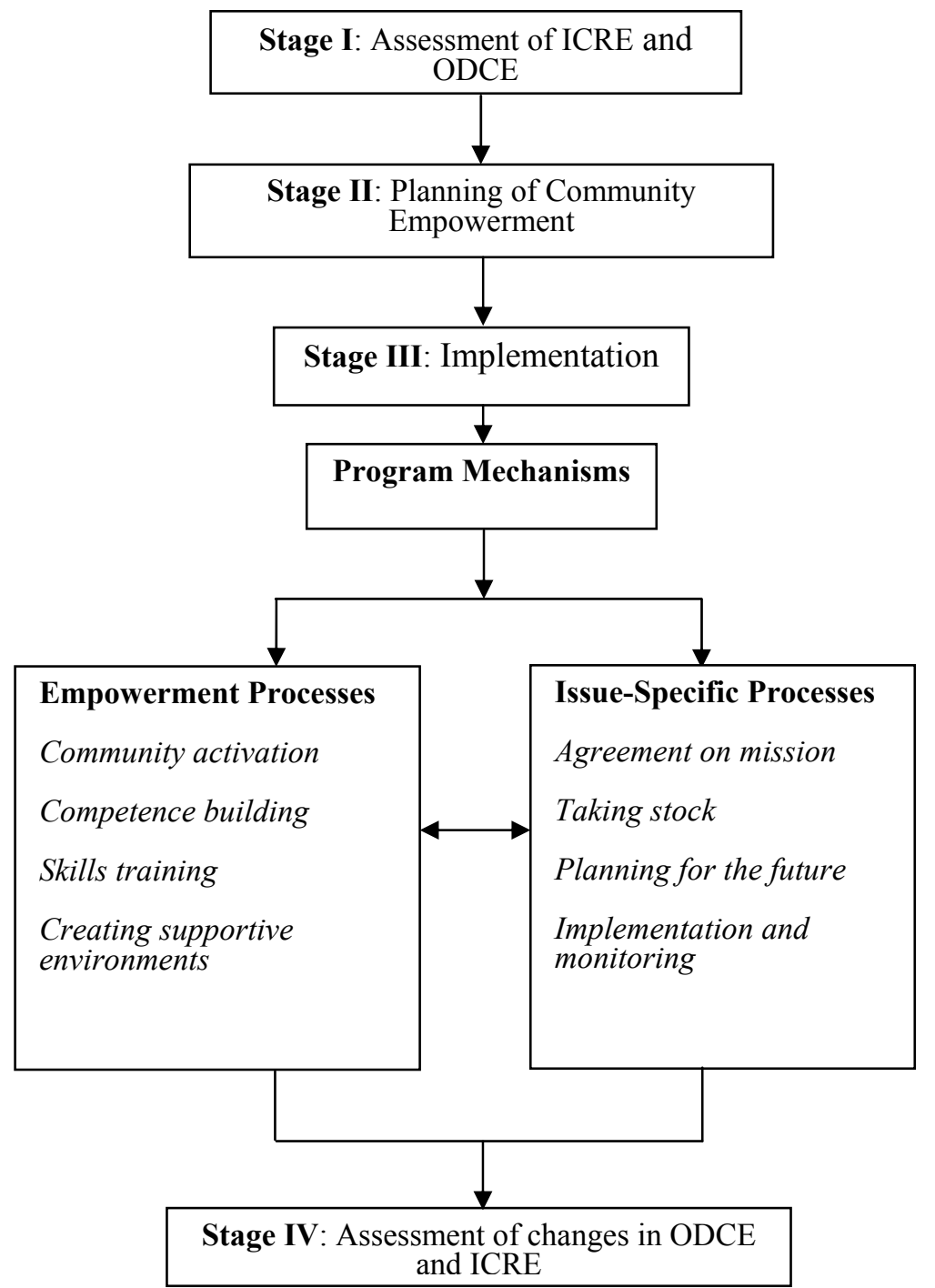

* Assessment of the organisational domains of community empowerment (ODCE) is not presented in this report.

The empowerment expansion framework creates an opportunity to simultaneously expand empowerment in a community, achieve expected outcomes related to community needs and evaluate changes in both tracks. The framework of the empowerment expansion comprised four stages:

Stage I - assessment of ICRE (undertaken by an external evaluator among the participants in the three community programs) and evaluation of the organisational domains of community empowerment (ODCE). The latter process is beyond the scope of the current study and is not reported here.

Stage II-planning of community empowerment. This included the formulation and statement of the empowerment expansion (undertaken by workgroups in each of the three community programs, where goals and objectives for the empowerment expansion were defined; measurable indicators and measurement processes were identified; and action plans were agreed upon).

Stage III — consisted of two parallel implementation processes: 
(a) Empowerment expansion processes: included numerous activities targeted at the development of the four ODCE domains (Table 2). These processes were debated, formulated and planned by the community while being supported, facilitated and mediated by a health promotion practitioner and an internal evaluator; and

(b) Issue-specific processes: during which the guidelines for empowerment evaluation [36] were used, and four actions were undertaken:

(i) agreement on an issue-specific mission;

(ii) taking stock (activities undertaken thus far were assessed, listed, analysed and rated, and an evaluation matrix was developed);

(iii) future planning (development of issue-specific goals and expected outcomes and formulation of an action plan). This also included the selection of measurement tools, indicators and a time-schedule for the issue-specific evaluation; i.e., the creation of a system of processes and outcome monitoring;

(iv) implementation. Table 3 depicts some activities that were undertaken by community workgroups during the issue-specific processes.

Stage IV - evaluation of changes in community members' ICRE (and assessment of the ODCE, which is not in the scope of the current paper).

Table 2. Examples of empowerment expansion processes: ODCE domains and corresponding activities that were implemented [35].

\begin{tabular}{|c|c|}
\hline Domain & Activities \\
\hline $\begin{array}{l}\text { Community } \\
\text { activation }\end{array}$ & $\begin{array}{l}\text { - Activities to support community members' participation in community } \\
\text { problem-solving processes } \\
\text { - Involvement and engagement of more stakeholders } \\
\text { - Motivation of new leaders } \\
\text { - Creation and encouragement of new networks } \\
\text { - Initiation and stimulation of new community groups among other processes }\end{array}$ \\
\hline $\begin{array}{l}\text { Community } \\
\text { competence }\end{array}$ & $\begin{array}{l}\text { - Training to improve the awareness and knowledge of community members to solve } \\
\text { community problems } \\
\text { - Distribution of information on good practices and evidence-based approaches } \\
\text { - Information sharing to improve understanding of concepts, determinants and theories in } \\
\text { health promotion among other processes }\end{array}$ \\
\hline $\begin{array}{l}\text { Program } \\
\text { management } \\
\text { skills }\end{array}$ & $\begin{array}{l}\text { - Teaching program management and team building skills } \\
\text { - Training for planning, implementation and evaluation techniques } \\
\text { - Instruction on information use, dissemination and communication skills } \\
\text { - Improving community groups, abilities and expertise in the use of evidence-based } \\
\text { techniques in identifying, solving and managing their problems among other processes }\end{array}$ \\
\hline $\begin{array}{l}\text { Creation of } \\
\text { supportive } \\
\text { environment }\end{array}$ & $\begin{array}{l}\text { - Training community members in lobbying skills } \\
\text { - Advocating for political support and financial resources } \\
\text { - Promoting better access to different foundations and expert resources } \\
\text { - Improving participants' abilities to maintain and sustain political changes and achieve a } \\
\text { large amount of social support, among other processes }\end{array}$ \\
\hline
\end{tabular}

ODCE: organisational domains of community empowerment. 
Table 3. Issue-specific processes: some activities undertaken by community workgroups [35].

\begin{tabular}{ll}
\hline Community Initiative & \multicolumn{1}{c}{ Issue-Specific Activities } \\
\hline Safe Community & - Organising safety campaigns \\
& - Teaching school-children traffic behaviour \\
& - Publishing printed materials for mothers of newborn babies on the prevention of \\
& babies' injuries \\
& - Organising swimming courses to prevent drowning \\
& - Implementing safe school campaigns \\
& - Publishing printed materials for elderly persons to prevent falls \\
& - Distribution of grants to stimulate small prevention projects \\
\hline Drug Abuse and AIDS & - Lobbying local policy makers to support the regulation of night sales of alcohol and \\
& to reduce youths' access to alcohol \\
Prevention & - Organising alternative activities for youth (summer-camps, drug-free discos) \\
& - Implementing an anti-AIDS campaign and the distribution of condoms to \\
& young people \\
& - Producing printed material on sexual education for young people \\
\hline Elderly Quality of Life & - Organising physical activity events in nature and in sport halls \\
& - Organising picnics and cultural outings \\
& - Inviting experts to talk on and debate health issues \\
& - Undertaking social support visits to peers \\
& - Implementing elderly Health Days \\
\hline
\end{tabular}

\section{Methods}

\subsection{Data}

Two sets of data were collected. Ethical committee approval was not sought because in Estonia, studies that involve the voluntary participation of adults and have informed consent are exempt from further ethical approval.

The first dataset was used to investigate the multidimensional nature of the ICRE construct in the Estonian context and to assess the content validity and reliability of its dimensions. Questionnaires to be self-completed were mailed by regular post during April-May 2003 to a cross-sectional random sample of 1,000 inhabitants from Rapla County (selected from the National Population Register). Two reminders were subsequently mailed to those individuals who did not respond. The response rate was 67.1\%. Respondents' $(\mathrm{n}=671)$ ages ranged from 17 to 71 years (Mean $=42 ; \mathrm{SD}=14.18$ ). $392(58.42 \%)$ female and 279 (41.58\%) male respondents were included.

The second dataset was employed to assess changes in participants' ratings of the dimensions of the ICRE. This sample consisted of all 120 voluntary participants from the three community programs who were involved in at least two program activities during the first intervention year of any of the three programs before the implementation of the empowerment expansion model. Two waves of the same self-administered questionnaire that was utilised for the first dataset were sent electronically: the first wave was sent one month before the first workshop related to application of the empowerment expansion framework in each community program separately (pre-test, 2003); and the second wave was sent after the last (third) workshop of the programs (post-test, January 2005). Additionally, two 
electronic reminders were sent to non-respondents, and phone interviews were undertaken with three individuals who did not respond electronically.

The pre-test was undertaken in 2003 (response rate 100\%). Respondents' $(\mathrm{n}=120)$ ages ranged from 24 to 65 years $($ Mean $=43$; SD = 10.9), and the sample comprised $78(65 \%)$ women and 42 $(35 \%)$ of men (Table 4$)$. Of these participants, $22 \%$ had attained a primary level of education, $61 \%$ a secondary level, and $37 \%$ of the participants had a university education. With respect to the employment and affiliation of these individuals 19,16\% were retired community members; $14,6 \%$ were people from the non-governmental sector; 10,83 worked in agriculture; $9,16 \%$ worked in the preschools and the same percentage in social work; $7,5 \%$ in the education system; $6,6 \%$ worked in the service and the same percentage in recreation sector; 3,33\% were civil servants and students; $5 \%$ worked in the health care system; 2,50\% were unemployed during the first measurement. In 2005, the post-test was undertaken. A total of 115 completed questionnaires were received during the post-test, which represented $95.8 \%$ of the pre-test participants. Five of the respondents who completed the pre-test had subsequently moved away from the community or were not available and, hence, were excluded from the current analysis. The mean age was $45(\mathrm{SD}=10.51)$, and the sample consisted of $73(63.48 \%)$ women and $42(36.52 \%)$ of men.

Table 4. Selected socio-demographic characteristics of respondents.

\begin{tabular}{|c|c|c|c|c|}
\hline \multirow{2}{*}{ Characteristics } & \multicolumn{2}{|c|}{ Year 2003} & \multicolumn{2}{|c|}{ Year 2005} \\
\hline & $\mathbf{N}$ & $\%$ & $\mathbf{N}$ & $\%$ \\
\hline Total & 120 & 100 & 115 & 95.8 \\
\hline \multicolumn{5}{|l|}{ Gender } \\
\hline Male & 42 & 35.00 & 42 & 36.52 \\
\hline Female & 78 & 65.00 & 73 & 63.48 \\
\hline \multicolumn{5}{|l|}{ Age } \\
\hline Range y & \multicolumn{2}{|c|}{$24-65$} & \multicolumn{2}{|c|}{$25-65$} \\
\hline Mean y SD & \multicolumn{2}{|c|}{$43(10.90)$} & \multicolumn{2}{|c|}{$45(10.51)$} \\
\hline \multicolumn{5}{|l|}{ Education } \\
\hline Primary & 22 & 18.33 & 19 & 16.52 \\
\hline Secondary & 61 & 50.83 & 61 & 53.04 \\
\hline University & 37 & 30.83 & 35 & 30.43 \\
\hline \multicolumn{5}{|l|}{ Affiliation } \\
\hline Retired & 23 & 19.16 & 21 & 18.26 \\
\hline Non-governmental sector & 17 & 14.16 & 19 & 16.52 \\
\hline Agriculture sector & 13 & 10.83 & 13 & 11.30 \\
\hline Pre-school & 11 & 9.16 & 11 & 9.56 \\
\hline Social sector & 11 & 9.16 & 11 & 9.56 \\
\hline Education sector & 9 & 7.50 & 9 & 7.83 \\
\hline Recreation & 8 & 6.66 & 8 & 6.96 \\
\hline Service & 8 & 6.66 & 8 & 6.96 \\
\hline Students & 7 & 5.83 & 5 & 4.35 \\
\hline Health care sector & 6 & 5.00 & 6 & 5.22 \\
\hline Civil servants & 4 & 3.33 & 4 & 3.48 \\
\hline Unemployed & 3 & 2.50 & - & - \\
\hline
\end{tabular}




\subsection{Instruments: Questionnaire (Mobilization Scale-Individual)}

There are few instruments that measure ICRE. For instance, Israel et al. [22] developed a 12-item perceived control scale to assess empowerment at individual, organisational and community levels (internal consistency $\alpha=0.63$ ). Similarly, Oman et al. [38] proposed a 6-item community involvement scale, and Reinigen et al. [12] suggested a youth empowerment scale (both with $\alpha=0.78$ ). Likewise, Spreitzer [9] developed a tool to evaluate IE in the workplace environment (12 items) that had a reliability coefficient 0.72 . The present study utilised the mobilization scale-individual [39]. This scale was selected because most of the scale's items emphasised participants' perceptions of having the requisite abilities and motivations to make a difference in their communities. The original scale consists of nine subscales and 49 propositions. Five subscales (self-efficacy, participation, motivation, social assets and human capital) consisting 30 questions were selected as most appropriate for study context. The questionnaire was translated from English into Estonian language by two translators independently. Thereafter, the method of back-translation [40] was employed to determine the equivalence between the primary and secondary language tools. After the back-translation, the original and back-translated questionnaires were compared, and points of divergence were noted. The scale components were modified during a workshop in which Rapla community members were invited to respond to the items and discuss their cultural understanding and relevance to their community.

The content validity of the translated questionnaire was assessed by an expert panel of six health promotion experts. Each item in the questionnaire was discussed and rated as 'essential' (1) or 'not necessary' ( 0 ), and the content validity ratio (CVR) was calculated using the formula developed by Lawshe [41].

The final questionnaire consisted of 20 items rated on a Likert-type five-point scale ( 1 = 'strongly agree', the most favourable perception, to $5=$ 'strongly disagree', the most unfavourable perception). The questionnaire considered the multidimensional nature of empowerment and allowed the assessment of the five dimensions of ICRE: self-efficacy related to an individual's attitude toward social change in the community ( 7 items, e.g., "I have confidence in my capabilities to make the changes needed in my community"); participation in community activities (3 items, e.g., "I participate in community activities"); intention to become involved in community change (4 items, e.g., "I intend to take action in my community"); motivation to be involved (3 items, e.g., "I am motivated to get involved in my community"); and critical awareness that community issues are serious (one item, "I think that the problems in my community are serious"). Collectively, these dimensions provided a broad picture of ICRE.

\subsection{Data Analysis}

The software package SPSS 12.0 was used for the statistical analysis of the data. For the first objective of the study, to assess the construct validity of the ICRE scale, we employed Lawshe's [41] formula: $\mathrm{CVR}=(\mathrm{n}<$ item $>\mathrm{e}+\mathrm{n}<$ item $>\mathrm{e}) /(\mathrm{N} \times \mathrm{n})$, where ne $=$ number of experts rating essential, and $\mathrm{N}=$ number of items. To investigate the multidimensional nature of the ICRE construct within the Estonian context, the first dataset was used, for which factor analysis was employed to extract the factors by applying principal components analysis (varimax rotation) (Table 5). To assess the reliability of the ICRE scale, we used internal consistency coefficients measured by Cronbach's alpha, 
which were undertaken twice: collectively for the total empowerment scale and individually for each of the five empowerment dimensions. To assess the changes in the participants' ratings of the dimensions of the ICRE before and after the application of the empowerment expansion framework, we compared the pre-test and post-test results using an independent sample $t$ test (one way ANOVA). Significance level was set at $p<0.5$.

Table 5. Assessment of the ICRE scale: principal components analysis.

\begin{tabular}{|c|c|c|c|c|c|c|}
\hline \multirow{2}{*}{ Dimension } & \multirow{2}{*}{ Items } & \multicolumn{5}{|c|}{ Component } \\
\hline & & 1 & 2 & 3 & 4 & 5 \\
\hline 1. Self-efficacy & - I have the knowledge and skills to influence the community & 0.774 & & & & \\
\hline \multirow{6}{*}{$\alpha=0.883$} & - I have the ability to impact my community in important ways & 0.771 & & & & \\
\hline & $\begin{array}{l}\text { - I have confidence in my capabilities to make needed changes } \\
\text { in my community }\end{array}$ & 0.755 & & & & \\
\hline & - I am able to affect the area in which I live & 0.743 & & & & \\
\hline & $\begin{array}{l}\text { - I can influence community members to take actions on } \\
\text { important issues }\end{array}$ & 0.671 & & & & \\
\hline & $\begin{array}{l}\text { - I have the knowledge and skills to gather information relevant } \\
\text { to my community }\end{array}$ & 0.647 & & & & \\
\hline & - I know I can make a differences in my community & 0.561 & & & & \\
\hline 2. Intention & - I want to get involved in my community & & 0.814 & & & \\
\hline \multirow[t]{3}{*}{$\alpha=0.834$} & - I am willing to get involved in my community & & 0.786 & & & \\
\hline & - I am going to get involved in my community & & 0.759 & & & \\
\hline & - I intend to take action in my community & & 0.603 & & & \\
\hline 3. Participation & - I participate in community activities & & & 0.697 & & \\
\hline \multirow[t]{2}{*}{$\alpha=0.808$} & - I am involved in my community & & & 0.562 & & \\
\hline & - I volunteer for community projects & & & 0.512 & & \\
\hline 4. Motivation & - I think it is important for me to get involved in my community & & & & 0.558 & \\
\hline \multirow[t]{2}{*}{$\alpha=0.69$} & - I feel that efforts to address community issues are worthwhile & & & & 0.522 & \\
\hline & - I am motivated to get involved in my community & & & & 0.508 & \\
\hline $\begin{array}{l}\text { 5. Critical } \\
\text { awareness }\end{array}$ & - I think that the problems in my community are serious & & & & & 0.707 \\
\hline \multirow[t]{2}{*}{ Excluded } & - I pitch in when there is work to be done & 0.230 & 0.396 & 0.485 & 0.249 & 0.310 \\
\hline & - I feel that community issues are important & 0.136 & 0.374 & 0.406 & 0.462 & \\
\hline \multicolumn{2}{|c|}{ Explained variance of ICRE (\%) } & 20.37 & 16.96 & 110.97 & 70.22 & 60.39 \\
\hline
\end{tabular}

Extraction method: principal components analysis; rotation method: varimax with Kaiser Normalization.

\section{Results}

\subsection{Study Objective 1: Construct Validity of the ICRE Scale}

Employing the formula suggested by Lawshe [41], the content validity ratio of the ICRE scale was 0.98, which is acceptable according to Davis [42] and Lawshe [41]. 


\subsection{Study Objective 2: Dimensionality—the Multidimensional Nature of the ICRE}

The dimensionality of the scale was evaluated by factor analysis (Table 5) using Kaiser's criterion (eigenvalue $>1$ ) [43]. The Kaiser-Meyer scale was .93, which is defined as very good [43]. Table 5 shows that five ICRE dimensions (factors) (i.e., self-efficacy, intention, participation, motivation and critical awareness) emerged relatively clearly. However, two items (intention- "I pitch in when there is work to be done", and critical awareness - "I feel that community issues are important") exhibited fairy low loadings on their associated factors and relatively high loadings on other components. All remaining factors presented relatively strong loadings on their individual components. The factors consisted of three to seven items each (though only one item for the factor critical awareness). Collectively, the five dimensions explained $62.91 \%$ of the variance in ICRE. With respect to each of the individual dimensions, self-efficacy explained $20.37 \%$ of the variance, intention $16.96 \%$, participation $11.97 \%$, and motivation $7.22 \%$. Their corresponding Eigen values (a common criterion for a dimension to be useful) were 8.52, 1.91, 1.25 and 1.02 [44].

\subsection{Study Objective 3: Reliability of ICRE}

Cronbach alpha coefficients were used to assess the reliability of the scale (Table 5). The internal consistency (Cronbach's $\alpha$ ) of the total scale was 0.859 , which is very good [45]. Likewise, the internal consistencies of the three sub-scales comprising three dimensions (Self-efficacy 0.883; Intention 0.834; Participation 0.808) were very good. The Motivation dimension had a lower $\alpha(0.69)$, which is considered satisfactory. Critical awareness comprised only one item, and hence, $\alpha$ was not applicable.

\subsection{Study Objective 4: Comparison of Pre- and Post-Test Ratings of ICRE Dimensions (Before and} After the Application of the Empowerment Expansion Model)

Table 6 presents the means and standard deviations of the empowerment scale at the beginning of the application of the empowerment expansion framework and two years after its application. Generally, the means of the post-test (2005) for the five dimensions of empowerment and for total empowerment were more favourable than their pre-test means (2003). These changes were statistically significant for four of the five dimensions (self-efficacy, participation, intention, and motivation).

Table 6. Comparison of participants' ratings of ICRE and its dimensions before and after the application of the empowerment expansion framework (pre- and post-test).

\begin{tabular}{|c|c|c|c|c|c|c|c|}
\hline & \multicolumn{2}{|c|}{$\begin{array}{c}\text { Pre-Test } 2003 \\
\mathrm{~N}=120\end{array}$} & \multicolumn{2}{|c|}{$\begin{array}{c}\text { Post-Test } 2005 \\
\mathrm{~N}=115\end{array}$} & \multirow[t]{2}{*}{$t$-value } & \multirow[t]{2}{*}{ DF } & \multirow[t]{2}{*}{$p$} \\
\hline & Mean & $\mathrm{SD}$ & Mean & $\mathrm{SD}$ & & & \\
\hline Empowerment (Total scale) & 1.87 & 0.37 & 1.82 & 0.35 & 3.179 & 225 & $0.002 *$ \\
\hline Self-efficacy & 2.12 & 0.43 & 2.07 & 0.41 & 2.345 & 225 & $0.020 *$ \\
\hline Participation & 1.70 & 0.56 & 1.64 & 0.52 & 2.245 & 225 & $0.026 *$ \\
\hline Intention & 2.02 & 0.54 & 2.01 & 0.49 & 3.192 & 225 & $0.002 *$ \\
\hline Motivation & 1.83 & 0.56 & 1.73 & 0.64 & 2.173 & 225 & $0.031 *$ \\
\hline Critical awareness & 1.68 & 0.33 & 1.62 & 0.31 & 1.668 & 225 & 0.097 \\
\hline
\end{tabular}


These findings suggested that respondents' perceptions of their self-efficacy related to community problem-solving had increased in 2005 in comparison with the 2003 data. Participants' confidence in their capabilities to undertake the required changes in their communities had increased, as respondents felt they could influence their communities to take action on important issues. Furthermore, respondents' motivation to participate, intention to participate and actual participation in community activities had all increased. Similarly, respondents' critical awareness of the seriousness of the community issues also exhibited a moderate increase, although the increase was not significant. Nevertheless, the 2003 data indicated that the critical awareness component of empowerment already presented a high value during the pre-test period, suggesting that for these three programs, respondents' baseline awareness of community problem seriousness was already high before the initiation of the programs.

\section{Discussion}

Given that expansion of empowerment is frequently the primary objective of community health promotion programs, the positive change in ICRE among the participants of the programs investigated in this study is gratifying. The empowerment of communities has been recognised as a key purpose and critical function of health promotion initiatives [31,32,46,47]. Not surprisingly, numerous health promotion efforts have employed empowerment as a vehicle for their programs to combat a range of health and social problems. The types of such programs in which empowerment strategies have been used are diverse and are related to, e.g., violence against women [48], promotion of mental health [49], maternal and reproductive health among internally displaced communities [50], and the reduction of sex workers' vulnerability to HIV/STDs [51]. Similarly, empowerment has been successfully utilised in decreasing the burden of lymphatic filariasis [52], in dengue prevention [53] and in the Healthy Cities movement [54].

However, few studies studies on this topic have previously been reported from eastern European countries, and there remains a gap in the empowerment literature in terms of research undertaken in (post-communist) countries that are in political and economic transition, such as Estonia. The current study bridges this gap, and while Estonia is classified economically as a high-income country [55], the current study was undertaken in a mainly rural area of Estonia where the relative poverty of the county's population was high in comparison to other regions of Estonia [34]. In such settings, the empowerment of community members through program participation has been shown to be particularly important [56]. This is probably because 'empowerment' mechanisms engender a belief in oneself that is accompanied by taking responsibility in community development.

The current study employed an empowerment expansion framework based on models of empowerment evaluation and 'parallel tracks' program planning [36,37]. Using this framework, program participants from three community health promotion initiatives were empowered through: (1) a range of empowerment activities (e.g., community activation, competence building and skills training, in addition to the creation of supportive environments) and (2) a variety of issue-specific actions (e.g., agreement on a mission, taking stock, planning for the future, implementation and monitoring). The post-test findings indicated that the employed empowerment processes were associated with enhanced feelings regarding self-efficacy related to social change in the community, 
participation in community activities, intention to become involved in community change, motivation to be involved, and critical awareness that community issues are serious.

Tools for the measurement of ICRE are still under development. This study undertook an initial step towards examining ICRE in the Estonian context. Hence, we adopted a mobilization scale-individual [39] that measures individual community-related empowerment. We validated the scale, which demonstrated a satisfactory five-factor solution, confirming five specific dimensions of ICRE. Factor analysis indicated that the first factor, self-efficacy, was one of the strongest and most consistent. This is in agreement with findings reported in the USA by Rogers et al. [57], who studied the individual empowerment of 271 participants in self-help groups in six states. Our results are also in support of the findings of Wowra and McCarter [13], who validated an empowerment scale in an adult outpatient mental health population in South Carolina among 283 patients and similarly reported that self- efficacy was the strongest dimension.

Likewise, the dimensions participation and intention to participate in community actions imply the ability and willingness to participate, which is in agreement with the results of a study by Eklund [27] among two Finnish communities where she found increased participation and intention to participate in community initiatives after utilising empowerment strategies. The results of Bejerholm and Björkman's research among people with mental illness entering supported employment in Sweden demonstrated a higher level of engagement in daily activities [58]. In a study undertaken by Röger et al. [59] among disadvantaged women in Germany, participation in community initiatives was found to be better among empowered individuals.

Our findings related to the dimension motivation to participate in the community, as an important component of ICRE, are in line with those of Mok et al. [11], who studied individual empowerment among Chinese cancer patients in Hong Kong. They found that the motivation dimension was critical for IE. Similarly, our findings regarding the dimension critical awareness are in agreement with the results of a study by Champeau and Shaw [60] in which they examined critical consciousness in the dynamics of a public health community collaboration around an HIV prevention media campaign for women in the USA and observed its importance in ICRE.

In our sample, the five factors described above emerged sufficiently clearly. Although the factor critical awareness comprised only one item, the ICRE scale proved to be valid and appropriate for the measurement of its dimensions. Furthermore, the reliability coefficient for the total empowerment scale $(\alpha=0.859)$ demonstrated very good internal consistency [45].

Our findings confirmed that the framework for ICRE adapted and utilised in the current study is consistent with the definitions of ICRE offered by Zimmerman and Rappaport [25] and Bracht and Tsouros [31]. The features constituting ICRE included community members' self-efficacy and confidence in their personal capability to organise and execute the course of action required to deal with community problems; participation, motivation and intention to participate without pay to achieve a common goal and/or social change in their community; and critical awareness as the sense of importance of community issues and understanding of the purpose of community action. Our findings are consistent with those of Bejerholm and Björkman [58], who studied people with mental illness entering supported employment and found that the use of multilevel empowerment approaches to health are required to support individual empowerment. 
Comparison of the pre- and post-test scores for the five dimensions revealed that all dimensions were improved in the post-test. The findings demonstrated a significant increase both in total empowerment and in four (of the five) dimensions related to perceived ICRE. A somewhat unexpected finding was the absence of a significant change in the fifth dimension, critical awareness of community issues. A likely reason for this might be the relatively high score for critical awareness already prevalent in the pre-test, or alternatively, the provision of insufficient focus on this particular dimension in the intervention. Nevertheless, a slight increase was also observed in the dimension critical awareness. Thus, the ICRE scale was shown to allow the researchers and community members to determine the levels of ICRE as perceived by community members before and after the implementation of an empowerment expansion model in three community programs. Furthermore, it provided members of the community workgroups with valuable information about factors that could be modified to achieve even more favourable ICRE among participants in the community programs.

The current study has limitations. Respondents from three health promotion programs from one county in Estonia participated in the study. This geographical limitation means that similar assessments in other regions and with larger sample sizes would be required to confirm or refute the present findings. Additionally, the community workgroups and network members who participated in the current study consisted of individuals with a heightened sense of social responsibility and social activity, as suggested by the fact they were already involved in a range of community development processes. Further studies are needed to apply the framework in more and different communities. Similarly, individuals may be greatly influenced by the context and other unanticipated events in their communities, which might influence their ICRE. Although this study affirmed that ICRE became more favourable during the intervention period, it is not possible to conclude that this materialised due to the health promotion interventions that we assessed. Furthermore, due to the cross-sectional nature of the current study, the observed trends are associations and should not be viewed as causations.

This study holds important implications for health promotion practice. Health promotion practitioners working with community networks might benefit from scrutinising the ICRE dimensions in the specific community contexts in which they work in a precise manner. Furthermore, asserting community members' empowerment status (and its dimensions) prior to a planned intervention could be beneficial for needs assessment exercises in terms of the dimensions of ICRE that might require strengthening to ensure effective program planning to meet the particular needs of the community members. Thus, the use of an empowerment expansion framework described here by communities could assist them in focussing on particular ICRE dimensions, which might then become essential and integral parts of a given community health promotion program. The findings of the present study suggested that to empower community members as part of a planned effort, community workgroups, together with local health promotion practitioners and evaluators, could direct their efforts to deliberately planned activities that would increase community members' self-efficacy, participation, motivation and intention to participate in community actions, as well as critical awareness of community issues. 


\section{Conclusions}

The current study aimed to assess changes in community members' ratings of ICRE after two years of application of an empowerment expansion framework in Rapla County, Estonia. Comparison of the scores from pre- and post-tests revealed that all dimensions of ICRE were improved in the post-test. Our findings demonstrated a significant increase both in total empowerment and in four (of the five) dimensions of perceived ICRE, as well as a slight non-significant increase in one item, critical awareness. To clarify the concept of ICRE, the empowerment scale was adapted to the community context, and factor analysis was utilised to identify its dimensions. A five-dimension ICRE scale emerged from the factor analysis, which was congruent with results reported in the literature, confirming the usefulness of ICRE characterised by the context-specific dimensions of perceived self-efficacy, self-reported participation, intention and motivation to participate in community actions and critical awareness of the seriousness of community problems. The internal consistency of the ICRE scale was very good. However, future studies in different communities and community workgroups will be necessary to elaborate the scale as a measurement instrument for the assessment of ICRE in community empowerment initiatives. We conclude that for the investigated Rapla community workgroups and networks, ICRE was rendered more favourable after the implementation of the empowerment expansion framework among the three health promotion programs. However, the cross-sectional study design employed here does not allow the demonstration of a cause-and-effect relationship between the intervention and ICRE outcomes.

\section{Acknowledgement}

This research was funded by the University of Southern Denmark and supported by the Rapla County Government. The authors thank the Rapla County community Safe Community, Drug Abuse and AIDS Prevention and Elderly Quality of Life program participants and county health promotion practitioners for ongoing support and Glenn Laverack and Walid El Ansary for providing suggestions for the present study.

\section{References}

1. World Health Organisation. Declaration of Alma-Ata. 1978. Available online: http://www.who.int/hpr/NPH/docs/declaration_almaata.pdf (accessed on 24 November 2010).

2. World Health Organisation. Ottawa Charter for Health Promotion. 1986. Available online: http://www.who.int/hpr/NPH/docs/ottawa_charter_hp.pdf (accessed on 24 November 2010).

3. Wallerstein, N. What Is the Evidence of Effectiveness of Empowerment to Improve Health? WHO/EURO: Copenhagen, Denmark, 2006.

4. Rappaport, J. Studies in empowerment: Introduction to the issue. Prev. Human Serv. 1984, 3, $1-25$.

5. Minkler, M. Improving Health through Community Organization and Community Building: A Health Education Perspective. In Community Organizing \& Community Building for Health; Minkler, M., Ed.; Rutgers University Press: London, UK, 2005; pp. 30-52. 
6. Fawcett, S.B.; Paine-Andrews, A.; Francisco, V.T.; Schultz, J.A.; Richter, K.P.; Berkley-Patton, J.; Fisher, J.L.; Lewis, R.K.; Lopez, C.M.; Russos, S.; et al. Evaluating Community Initiatives for Health and Development. In Evaluation in Health Promotion: Principles and Perspectives; Rootmann, I., Goodstadt, M., Hyndman, B., McQueen, D.V., Potvin, L., Springhet, J., Ziglio, E., Eds.; WHO/EURO: Copenhagen, Denmark, 2001; pp. 241-270.

7. Prilleltenski, I. Empowerment in mainstream psychology: Legitimacy, obstacles, and possibilities. Can. J. Psychol. 1994, 35, 358-374.

8. Speer, P.W.; Hughey, J. Community organizing: An ecological route to empowerment and power. Am. J. Community Psychol. 1995, 23, 729-748.

9. Spreitzer, G.M. Psychological empowerment in the workplace: Dimensions, measurement and validation. Acad. Manag. J. 1995, 38, 1442-1465.

10. Becker, J.; Kovach, A.C.; Gronseth, D.L. Individual empowerment: how community health workers operationalize self-determination, self-sufficiency, and decision-making abilities of low-income mothers. J. Community Psychol. 2004, 32, 327-342.

11. Mok, E.; Martinson, I.; Wong, T.K.S. Individual empowerment among Chinese cancer patients in Hong Kong. Western J. Nurs. Res. 2004, 26, 59-75.

12. Reinigen, B.; Evans, A.E.; Griffin, S.F.; Valois, R.F.; Vincent, M.L.; Para-Medina, D.; Taylor1, D.J.; Zullig, K.J. Development of a youth survey to measure risk behaviours, attitudes and assets: Examining multiple influences. Health Educ. Res. 2003, 18, 461-476.

13. Wowra, S.A.; McCarter, R. Validation of the empowerment scale with an outpatient mental health population. Psych. Serv. 1999, 50, 959-961.

14. Florin, P.; Wandersman, A. An introduction to citizen participation, voluntary organizations, and community development: insights for empowerment through research. Am. J. Community Psychol. 1990, 18, 41-54.

15. Chavis, D.; Wandersman, A. Sense of community in the urban environment: A catalyst for participation and community development. Am. J. Community Psychol. 1990, 18, 55-81.

16. Zimmerman, M.A. Empowerment Theory: Psychological, Organizational and Community Levels of Analysis. In Handbook of Community Psychology; Rappaport, J., Seidman, E., Eds.; Kluwer Academic/Plenum Publishers: New York, NY, USA, 2000; pp. 43-63.

17. Gutierrez, L.M. Understanding the empowerment process: Does consciousness make a difference? Soc. Work Res. 1995, 19, 229-237.

18. Parsons, R. Assessing Helping Processes and Client Outcomes in Empowerment Practice: Amplifying Client Voice and Satisfying Funding Sources. In Empowerment Practice in Social Work: Developing Richer Conceptual Foundations; Hera, W., Wells, L.M., Eds.; Canadian Scholars Press: Toronto, Canada, 1999.

19. McWhirter, E.H. Empowerment in counselling. J. Couns. Dev. 1991, 69, 222-227.

20. Akey, T.M.; Marquis, J.G.; Ross, M.E. Validation of Scores on the Psychological Empowerment Scale: A Measure of Empowerment for Parents of Children with a Disability. Educ. Psychol. Meas. 2000, 60, 419-438.

21. Speer, P.W.; Peterson, N.A. Psychometric properties of an empowerment scale: Testing cognitive, emotional and behavioural domains. Soc. Work Res. 2000, 24, 109-118. 
22. Israel, B.A.; Checkoway, B.; Schulz, A.; Zimmerman, M. Health education and community empowerment: Conceptualizing and measuring perceptions of individual, organizational, and community control. Health Educ. Quart. 1994, 21, 149-170.

23. Kieffer, C. Citizen Empowerment: A Developmental Perspective. In Studies in Empowerment: Steps Toward Understanding and Action; Rappaport, J., Swift, C., Hess, R., Eds.; The Haworth Press: New York, NY, USA, 1984; pp. 60-84.

24. Zimmerman, M.A. Taking aim on empowerment research: On the distinction between individual and psychological conceptions. Am. J. Community Psychol. 1990, 16, 725-750.

25. Zimmermann, M.A.; Rappaport, J. Citizen participation, perceived control, and psychological empowerment. Am. J. Community Psychol. 1988, 16, 725-750.

26. Dimidriades, Z.; Kufidu, S. Individual, job, organizational and contextual correlates of employment empowerment: some Greek evidence. Electron. J. Bus. Ethics Org. Stud. 2004, 9, $36-43$.

27. Eklund, L. From Citizen Participation towards Community Empowerment: An Analysis on Health Promotion from Citizens Perspective; PhD Thesis; University of Tampere: Tampere, Finland, 1999.

28. Davidson, W.B.; Cotter, P.R. Sense of community and political participation. J. Community Psychol. 1989, 17, 119-125.

29. McMillan, B.; Florin, P.; Stevenson, J.; Kerman, B.; Mitchell, R.E. Empowerment praxis in community coalitions. Am. J. Community Psychol. 1995, 23, 699-727.

30. Hirsch, E.L. Sacrifice for the course: Group processes, recruitment and commitment in a student social movement. Am. Sociol. Rev. 1990, 55, 243-254.

31. Bracht, N.; Tsouros, A. Principles and strategies of effective community participation. Health Prom. Int. 1990, 5, 199-208.

32. Wallerstein, N. Powerlessness, empowerment, and health: Implications for health promotion programs. Am. J. Health Prom. 1992, 6, 197-205.

33. Horvath, P. The organization of social action. Can. J. Psychol. 1999, 40, 221-231.

34. Rapla Maavalitsus. Rapla County and Its People; Rapla Maavalitsus: Rapla, Estonia, 2002.

35. Kasmel, A.; Andersen, P.T. Measurement of community empowerment in three community programs in Rapla (Estonia). Int. J. Environ. Res. Public Health 2011, 8, 799-817.

36. Fetterman, D.M. Empowerment Evaluation: An Introduction to Theory and Practice. In Empowerment Evaluation: Knowledge and Tools for Self-Assessment and Accountability; Fetterman, D.M., Kaftarian, S.J., Wandersman, A., Eds.; Sage: Thousand Oaks, CA, USA, 1996; pp. 3-46.

37. Laverack, G. Addressing the Contradiction between Discourse and Practice in Health Promotion; PhD Thesis; Deakin University: Melbourne, Australia, 1999.

38. Oman, R.F.; Vesely, S.K.; McLeroy, K.R. Reliability and validity of the Youth Asset Survey (YAS). J. Adol. Health 2002, 31, 247-255.

39. Jakes, S.; Shannon, L. Community Assets Survey. 2002. Available online: http://ag.arizona.edu/ fcs/cyfernet/nowg/Scale.PDF (accessed on 4 November 2004). 
40. Lin, Y.H.; Chen, C.Y.; Chiu, P.K. Cross-Cultural Research and Back-Translation. Sport J. 2005, $8,1-10$.

41. Lawshe, C.H. A quantitative approach to content validity. Person. Psychol. 1975, 28, 563-575.

42. Davis, L. Instrument review: Getting the most from your panel of experts. Appl. Nurs. Res. 1992, 5, 194-197.

43. DeVellis, R.F. Factor analysis, scale development theory and application. Appl. Soc. Res. Method Ser. 2003, 26, 10-137.

44. Morgan, G.A.; Griego, O.V. Easy Use and Interpretation of SPSS for Windows; Lawrens Erlbaum Associates Publishers: London, UK, 1998.

45. Sekaran, U. Research Methods for Business: A Skill Building Approach, 2nd ed.; John Willey \& Sons, Inc: New York, NY, USA, 1992.

46. El Ansari, W.; Phillips, C.J. Empowering health care workers in Africa: Partnerships in health-beyond the rhetoric towards a model. Critic. Pub. Health 2001, 11, 231-252.

47. Ridde, V. Reducing social inequalities in health: Public health, community health or health promotion? Promot. Educ. 2007, 14, 63-67.

48. Kalaca, S.; Dundar, P. Violence against women: The perspective of academic women. BMC Pub. Health 2010, 10, 490.

49. Taylor, J.; Jones, R.M.; O’Reilly, P.; Oldfield, W.; Blackburn, A. The Station Community Mental Health Centre Inc: Nurturing and Empowering. Rural Rem. Health 2010, 10, 1411.

50. Mullany, L.C.; Lee, T.J.; Yone, L.; Lee, C.I.; Teela, K.C.; Paw, P.; Shwe Oo, E.K.; Maung, C.; Kuiper, H.; Masenior, N.F.; Beyrer, C. Impact of community-based maternal health workers on coverage of essential maternal health interventions among internally displaced communities in Eastern Burma: the MOM project. PLoS Med. 2010, 7, e1000317.

51. Swendeman, D.; Basu, I.; Das, S.; Jana, S.; Rotheram-Borus, M.J. Empowering sex workers in India to reduce vulnerability to HIV and sexually transmitted diseases. Soc. Sci. Med. 2009, 69, 1157-1166.

52. Rajendran, R.; Sunish, I.P.; Munirathinam, A.; Ashok Kumar, V.; Tyagi, B.K. Role of community empowerment in the elimination of lymphatic filariasis in south India. Trop. Biomed. 2010, 27, 68-78.

53. Sanchez, L.; Perez, D.; Cruz, G.; Castro, M.; Kourí, G.; Shkedy, Z.; Vanlerberghe, V.; van der Stuyft, P. Intersectoral coordination, community empowerment and dengue prevention: Six years of controlled interventions in Playa Municipality, Havana, Cuba. Trop. Med. Int. Health 2009, 14, 1356-1364.

54. Heritage, Z.; Dooris, M. Community participation and empowerment in Healthy Cities. Health Promot. Int. 2009, 24, 145-155.

55. The World Bank. Country and Lending Groups, 2010. Available online: http://data.worldbank.org/ about/country-classifications/country-and-lending-groups\#Lower_middle_income.pdf (accessed on 12 January 2011).

56. Smith, M.A.; Garbharran, H.; Edwards, M.J.; O’Hara-Murdock, P. Health promotion and disease prevention through sanitation education in South Africa Zulu and Xhosa women. J. Transcult. Nurs. 2004, 15, 62-68.

57. Rogers, E.S.; Chamberlin, J.; Ellison, M.L.; Crean, T. A consumer constructed scale to measure empowerment among users of mental health services. Psych. Serv. 1997, 48, 1042-1047. 
58. Bejerholm, U.; Björkman, T. Empowerment in supported employment research and practice: Is it relevant? Int. J. Soc. Psychiatry 2010, doi:10.1177/0020764010376606.

59. Röger, U.; Rütten, A.; Frahsa, A.; Abu-Omar, K.; Morgan, A. Differences in individual empowerment outcomes of socially disadvantaged women: Effects of mode of participation and structural changes in a physical activity promotion program. Int. J. Public Health 2010, doi:10.1007/s00038-010-0214-8.

60. Champeau, D.A.; Shaw, S.M. Power, empowerment, and critical consciousness: Lessons learned from an advisory panel for an HIV awareness media campaign for women. Women Health 2002, $36,31-50$.

(C) 2011 by the authors; licensee MDPI, Basel, Switzerland. This article is an open access article distributed under the terms and conditions of the Creative Commons Attribution license (http://creativecommons.org/licenses/by/3.0/). 